Suleika Bort, Simone Schiller-Merkens: Reducing Uncertainty in Scholarly Publishing: Concepts in the Field of Organization Studies,

1960-2008. In: Schmalenbach Business Review 63(4), 337-360 (2011). Springer

The original publication is available at the publisher's web site: https://doi.org/10.1007/BF03396823

Suleika Bort/Simone Schiller-Merkens*

\title{
Reducing Uncertainty in Scholarly Publishing: CONCEPTS IN THE Field Of Organization StUdies, 1960-2008
}

\begin{abstract}
In this paper, we investigate the dynamics in the field of organization studies. We focus on the market for scholarly publishing and trace how many and which kinds of concepts have been developed and diffused in publications over the last 48 years. We argue that scholars in the publishing market must deal with two kinds of uncertainty: uncertainty on the delicate balance of maintaining research that is both novel and attentive to existing schools of thought, and uncertainty related to the heterogeneity of institutional logics that guide research in the field. We propose that concepts are a means of uncertainty reduction for two reasons. First, working with concepts allows considering both novelty and continuity. Second, working with concepts in a way that follows the dominant field logic helps to reduce uncertainty about what is valued as publishable in the field. We find that the number of concept articles in organization studies has increased, particularly concept articles that align with the dominant logic of positivism.
\end{abstract}

JEL-Classification: N01, Y8, Z0.

Keywords: Concept; Institutional Logic; Organization Studies; Positivism; Publish or Perish; Uncertainty.

\section{INTRODUCTION}

Since research evaluations have made their way into academia and because the "publish or perish" doctrine pressures researchers to increase their publishing, research activities are more and more embedded in an "intellectual market" in which scholars sell their ideas in exchange for publications in highly ranked journals (McKinley, Mone, and Moon (1999)).

* Suleika Bort, Department of Strategic and International Management, University of Mannheim, D-68131 Mannheim, phone: +49-621-181-1739, fax: +49-621-181-1738, e-mail: sbort@rumms.uni-mannheim.de. Simone Schiller-Merkens, University of Mannheim, D-68131 Mannheim, e-mail: schiller@orga.bwl.uni-mannheim.de.

** We are grateful to Axel Haunschild, Dodo zu Knyphausen-Aufseß, and Arnold Picot for their helpful comments on an earlier version of this paper. We also thank the participants at the Workshop of the Wissenschaftliche Kommission Organisation in 2010 for their suggestions. 
However, in this market having a good idea is not enough for being successful. To get a manuscript published in a top-tier journal, an idea must be regarded as being unique, one that can provide a new or better understanding of social and organizational phenomena (Barley (2006); Bartunek, Rynes, and Ireland (2006); Frey (2003); McKinley (2010); Staw (1995)). Originality though can be hard to achieve. Moreover, there are voices that doubt that originality is actually supported by the journals' publication practices (De Rond and Miller (2006); Frey (2003); Frey and Osterloh (2006); Frost and Taylor (1995); Staw (1995)). For instance, Staw $(1995,87)$ asserts that "deviant methods and ideas are screened out in the review process, [and that] authors are usually hesitant to break open new topics or to drop established procedures in dealing with organizational problems". Other authors note the influence of a "confirmation bias" (Miller (2006, 426)), the tendency of reviewers and editors to favor articles that do not deviate too much from what is regarded as the prevailing or preferred wisdom in the scientific community (see also Engwall (1998)).

The delicate balance between originality and attention to the prevailing research consensus is a source of uncertainty for the individual scholar. How can he or she be successful in the market of scholarly publications when confronted by this demand? We argue that concepts provide a means of uncertainty reduction. First, scholars can reflect their alignment with the scholarly field by working with or developing concepts that form part of the most legitimated schools of thought. Second, concepts allow to address the demand for originality. It is less complex and also more publishable with regard to the space limits of a journal article (Barley (2006)) to elaborate a concept instead of a whole theory. Thus, building an article around a concept can serve as a means of demonstrating both originality in the theoretical contribution and alignment with the popular schools of thought.

Organization scholars face another source of uncertainty. In the field of organization studies, several competing paradigms such as positivism, constructivism, and realism represent the logics guiding scholarly activities (Reed (2006)). The heterogeneity of and contradiction between these institutional logics (Friedland and Alford (1991); Thornton and Ocasio (1999)) is a source of uncertainty for the individual who seeks success in the scholarly publishing market. What counts as legitimate research conduct is contested in the field; the prevailing logics do not serve as undisputable guidelines. In this paper, we argue that to reduce uncertainty, a scholar will follow the dominant logic in the field when applying or developing concepts.

In general, we seek to contribute to the increasing interest of organization studies in the study of concepts. Suddaby (2010) states that management and organization theory are surprisingly silent on the nature and role of concepts in their field (see also Pfeffer (2005)). How concepts are created and used in the research process still remains comparatively underdeveloped. Although the work of Colquitt and Zapata-Phelan (2007), Hardy and Maguire (2008), Hirsch and Levin (1999), Mizruchi and Fein (1999), Osigweh (1989), Shenhav, Shrum, and Alon (1994), or Stevenson, Pearce, and Porter (1985) has already shown the important role of concepts in the field of organization studies, most of these studies focus on studying one or a few concepts when investigating its or their diffusion 
and historical evolution. However, by concentrating on one or only a few concepts and restricted time frames, these studies provide only a glimpse of the evolving field of organization studies.

We depart from these studies and investigate the plurality of concepts in the field of organization studies over a longer period of time. The kinds of concepts produced and reproduced can be seen as an outcome of research practices that reflect the underlying logics. Studying concepts thus provides insights into which logic dominates the field, whether its dominance is reproduced or whether other logics become dominant over time. We examine these dynamics in the market for scholarly publishing. We do so by tracing how many and which kinds of concepts developed and diffused in the period from 1960 to 2008. The results of our study indicate an increasing relevance of concepts in scholarly publishing in general, and also a continued prevalence of those kinds of concepts whose application is guided by the dominant research logic. Regarding the increasing uncertainty in the organization studies field, these findings lead us to conclude that under conditions of uncertainty, actors tend to refer to concepts more often and to reproduce the dominant logic even when alternative logics are available.

\section{Theoretical Background and Hypotheses}

\subsection{On the Role of Concepts in Organization Studies}

There are many different views in science of what a concept (or the synonym construct) actually is (Carnap (1995); Dubin (1969); Hempel (1974); Kaplan (1964); Suddaby (2010)). For example, Osigweh $(1989,591)$ states that "[c]oncepts are meaning-laden classifications that serve as building blocks of science". Bagozzi and Phillips (1982, 465) define "[t] heoretical concepts [as] abstract, unobservable properties or attributes of a social unit or entity". Bacharach $(1989,500)$ argues that a construct "can be conceptualized under an overall abstraction, and it is theoretically meaningful and parsimonious to use this overall abstraction as a representation of the dimension”. Thus, how concepts are defined and referred to in a particular research context is often accused of being "a matter of convention" (Carnap $(1995,59)$ ). Nonetheless, there is a common agreement that a concept "may be viewed as a broad mental configuration of a given phenomenon" (Bacharach $(1989,500))$. Concepts and their relationships comprise elements of a theory and can be viewed as its "intellectual products" (McKinley, Mone, and Moon (1999)). Thus, concepts receive their meaning from their relation to a theory, a characteristic that distinguishes them from popular management concepts such as "Lean Management" or "Total Quality Management", neither of which can be subsumed under a particular theory.

Since organizational concepts are an element of organization theories they provide a basis to demonstrate a scholar's continuity or alignment with widely accepted schools of thought and paradigmatic standards in the field of organization studies. McKinley, Mone, and Moon $(1999,637)$ refer to continuity as "a property of affinity: it means a linkage with intellectual frameworks that are already familiar to a scholar". Continuity 
is essential to understanding and encoding one another's work and to assess the respective contribution (Bartunek, Rynes, and Ireland (2006); Daft, Griffin, and Yates (1987); McKinley, Mone, and Moon (1999)). Research that proves its continuity by connecting to pre-existing knowledge is more likely to be published (Kaplan (1964)). Journal editors and reviewers are then able to relate the research to prevailing cognitive schemata and to evaluate its contribution relative to the current stock of scholarly knowledge. Continuity can thus be achieved by embedding research into a theoretical framework that is legitimated among the members of the scientific community, and one way to make this happen is by working with or referring to concepts.

While continuity is less widely discussed as a requirement for scholarly publications, originality in the sense of new theory development is among the most prominent goals in organization studies and is greatly rewarded in the field (Barley (2006); Bartunek, Rynes, and Ireland (2006); McKinley (2010); Pfeffer (1993)). McKinley, Mone, and Moon $(1999,637)$ refer to originality as novelty and define it as "the property of being new, unique, or different, particularly relative to theoretical frameworks that have been central to a discipline in the past". Developing concepts can be a way to address the demand for originality and to produce a novel theoretical contribution. Compared to the development of a whole new theory, it is less complex to elaborate concepts as the "units of theoretical statements" (Bacharach $(1989,496)$ ), and certainly far less difficult than to introduce a whole theory within the space limits of a journal article (Barley (2006)). Thus, working with concepts allows displaying novelty and continuity simultaneously. It is therefore a means of reducing uncertainty regarding the question of how to balance new and confirming elements in a paper (Weizsäcker (1974); Picot, Reichwald, and Wigand (2008)) to become or remain successful in scholarly publishing. Hence, given this role of concepts, we propose that the number of articles in organization studies publications that relate to concepts increases over time.

However, the pressure to publish continuously may constrain a scholar's capacity for theoretical development, even on the level of concepts. To bring a new concept into being presupposes great analytical skills, and is obviously also a time-consuming effort (Barley (2006); Sutton and Staw (1995)). But time is a rare resource, especially for young scholars under pressure to achieve tenure. Thus, it is likely that junior researchers seek to gain their reputational rewards by referring to concepts that are already accepted. Referring to existing concepts can happen in various ways, among which is the application of a concept in a novel domain of inquiry, using a new statistical method. Another way is to give a historical review of a particular concept, and of how and why this concept has been referred to at different times and in different research contexts. Lane, Koka, and Pathak's study (2006), which critically reviews and develops the concept of absorptive capacity, is illustrative. Lane, Koka, and Pathak (2006) make a detailed analysis of 289 absorptive capacity papers from 14 journals to analyze how the absorptive capacity concept has been utilized. They search for main papers assigned to the absorptive capacity concept and identify their contributions to the broader organization studies literature. Several other studies pursue a comparable approach (Denison (1996); Landry (1995); Mizruchi and Fein (1999); Osigweh (1989); Shenhav, Shrum, and Alon (1994); Stevenson, Pearce, and Porter (1985); Verbeke, Volgering, and Hessels (1998); Weingart and Maasen (1997)). 
The seeming relevance of pre-existing concepts is reflected not only in the junior researchers' activities, but also in the activities of other important field actors in the market for scholarly publishing, such as journal editors and reviewers. Although actively searching for unique theoretical contributions to organization studies, their day-to-day work is burdened with an incredible information overload (McKinley, Mone, and Moon (1999)). The sheer quantity of papers submitted is "overwhelming anyone's ability to read or even to keep track of them all" (Field (1993, 323); Jermier (1992); Klamer and Van Dalen (2002)). Hence, both reviewers and editors may be overburdened with honoring creative and novel contributions. Therefore, it is likely that they favor articles that make use of concepts with which they are already familiar. Overall then, time restrictions and information overload make recourse to already existing concepts by main field actors in the market for scholarly publishing - namely researchers, editors, and reviewers - likely, at the expense of new concept development. We therefore propose that the number of articles in organization studies that introduce new concepts decreases over time.

\subsection{The Field of Organization Studies and its Dominant Logic}

Kaplan $(1964,8)$ proposes the notion of logic to specify the norms and standards that govern the way of doing and rewarding "good" research in a scholarly field: "Logic, in short, deals with what scientists do when they are doing well as scientists". This notion resembles the definition of an institutional logic by Friedland and Alford (1991) where logic refers to the socially constructed patterns of activity and generalized social rules by which field actors produce and reproduce their material lives and render their day-to-day experiences meaningful. With reference to Burrell and Morgan (1979) we can thus argue that the institutional logics in a scholarly field refer to the generalized beliefs on the nature of the object under study, the conduct and the methods of its inquiry, and to the material practices through which these beliefs are reproduced. The field of organization studies is guided by competing institutional logics that incorporate heterogeneous and contradictory rules for appropriate research conduct. As noted above, this includes positivism, constructivism, and more recently, realism (Burrell and Morgan (1979); Knudsen (2003); Kuhn (1962); Morgan (1979); Pfeffer (1993); Scherer (2003); Whitley (2000); Reed (2006)). The ontological, epistemological, and methodological assumptions of these paradigms are generalized beliefs that shape research practices such as the creation or use of concepts, and are also reproduced by these practices.

The struggle between these paradigms as competing logics for guiding research activities is a source of uncertainty for the individual scholar. The contradictions between these belief systems make it difficult to assess what is generally considered a legitimate paradigmatic approach. Whitley $(2000,91)$ mentions the following characteristics of the field that are not particularly helpful to derive legitimate research practices: "weakly bounded groups pursuing a variety of goals with a variety of procedures, little co-ordination of results or problems, [and a] low extent of division of labour across research sites". Beckert (1999) notes a positive correlation between the level of uncertainty and the reproduction of institutions. He argues that the higher the uncertainty in a situation, the more likely actors will tend to pursue institutionalized practices. We extend this claim by arguing that in a 
situation in which several logics exist in a field, yet one logic is dominant, the individual scholar can reduce uncertainty by adopting practices that follow the dominant logic. In organization studies, the logic of positivism gained prominence in the formation years of the field and still seems to dominate activities (e.g., Nodoushani (2000)).

Scholars who analyze the historical development of organization studies note that the field has moved from a mélange of different disciplines into a field of its own, one which is related with a strong scholarly identity and an agreement upon a "standardized set of ancestors" (Augier, March, and Sullivan (2005, 85)). According to these scholars, two agents have had a particular influence on the early development of the field, the Ford Foundation and the Carnegie Foundation (De Rond and Miller (2006); Khurana (2007)). The donations of both these foundations have been dedicated to enhancing the previously low academic standing of management and organization studies and to supporting the scientification process of the field. To receive a grant from the Ford Foundation, researchers had to study its subject matter in a scientific manner, which meant applying research tools such as those linked with statistics, hypothesis testing, and mathematical analysis (Nodoushani (2000)). This requirement attracted scholars from disciplines such as psychology, sociology, political science, and in particular, economics, disciplines whose analytical and methodological rigor influenced the formation of the field and its leading institutional logic. These scholars strongly believed in a "sacred position of logical positivism" (Augier, March, and Sullivan (2005, 86)), and their understanding of doing research increasingly became the dominant logic in organization studies: "The hypothetical deductive method was to become a quintessential feature of so-called proper research. [...] Management, as a social science, came to perch the gap between the narrative world of organizations and the natural sciences, using the context of organizations but methods of the natural sciences for reasons of transparency, legitimacy, and respectability" (De Rond and Miller (2006, 323)). Camic and Xie (1994) further claim that the increasing use of statistical methods led "to demonstrate compliance with acceptable scientific models and at the same time carve out a distinctive mode of statistical analysis to differentiate their own discipline from the others" (Camic and Xie (1994, 773)). Hence, empirical, quantitative research in the tradition of positivism gave organization studies legitimacy as an academic discipline in the first place. Positivism helped to define the boundaries of the newly emerged field and provided the organization scholar the basis for building a reputable professional identity. Positivism and nomothetic inquiry (defined as relying on hypothesis testing and searching for general laws while honoring empirical, quantitative methods) came to be regarded as the proper way to do research.

Interestingly, the dominance of the positivist logic seems to persist today. Daft $(1980,623)$ was among the first to show this "sharp trend toward low-variety statistical languages" by analyzing the content of articles in Administrative Science Quarterly over a period of 24 years. More recently, Schminke and Mitchell (2003) sample the content of articles that appeared in the Academy of Management Journal over the past 45 years. Among the most striking trends, they show an increase in publications following the logic of positivism. In particular, they identify the minority position of qualitative work, a finding that is reflected in the relatively low percentage of articles related to qualitative research. Although 
some scholarly journals focus on publishing qualitative work (e.g., Organization Studies, Organization, Strategic Organization), and editorial essays in top-tier journals underscore the importance of qualitative research (e.g., Pratt (2009)), studies show that the majority of articles remain quantitative in their research design. The tendency of prestigious scholarly journals to favor empirical and quantitative articles (Mowday (1997)) is still striking. These journals are powerful actors in the field who indicate in which direction the research front is heading and what kind of questions and methodologies are gaining momentum (Tahai and Meyer (1999)). Other actors in the field, especially in situations in which uncertainty is relatively high (Beckert (1999)), are likely to regard the most prominent paradigm as a vehicle for success, and to pursue research activities that align with the logic supported by the powerful actors. We can thus assume that concepts that offer a methodology for positivist research are more likely to diffuse than concepts embedded in a non-positivist research frame. Hence,

\section{Hypothesis 1: The diffusion of concept articles that encompass a methodology for empirical, quantitative research is higher than the diffusion of concept articles that do not offer such a methodology.}

Studies show that the trend towards positivism is accompanied by an increase in empirical in contrast to theoretical articles (e.g., Nodoushani (2000)). For instance, Schminke and Mitchell (2003) observe a marked increase in the average number of pages dedicated to methods. Thus, we argue that it is likely that the empirical application of a concept, or at least the adding of detailed methodological advice in its publication, may raise a concept's attractiveness. An empirically applied concept entails detailed information on how it can be used empirically, and thus can more easily be transferred to and replicated in another empirical context. Therefore,

Hypothesis 2: The diffusion of articles in which concepts are empirically applied is higher than the diffusion of articles in which concepts are only theoretically discussed.

We may wonder whether the empirical application of a concept gains importance on its first presentation to the public. There are authors who argue that theoretical papers are particularly appealing and more likely to be picked up by other scholars in the field (Barley (2006); Daft, Griffin, and Yates (1987); Kieser (2007)). As Barley (2006, 18) asserts, "interesting 'theoretical' papers generally propose new models or metaphors that let us either see what we didn't see before or see in a new light what we thought we already understood. Compared to other types of papers, an interesting theoretical paper may have a better chance of becoming famous". Supposedly, a concept that is introduced within a theoretical article might be particularly inspiring by provoking different perspectives on known or previously unknown organizational phenomena. A theoretically introduced concept may stimulate a stream of further research activities, projects that discuss the concept's provocative break with preceding scholarly knowledge, and, others that eventually generate ways to measure and test it empirically. Hannan und Freeman's (1977) first published article on population ecology, for instance, was not an empirical, but a theoretical article. Today there are almost no other organizational concepts that are more often 
empirically applied than population ecology concepts like "niche", "fitness", or "environmental capacity". Accordingly,

Hypothesis 3: The diffusion of articles in which new concepts are introduced theoretically without any empirical application is higher than the diffusion of articles in which new concepts are introduced with an empirical application.

\section{Methods}

\subsection{SAMPLE}

Our data sample includes a selection of 39 different journals in the category of Business/Management (of which Organization represents a subcategory) that are generally considered as being among the most influential publications in the field (Harzing (2003); Hennig-Thurau, Walsh, and Schrader (2006); Podsakoff et al. (2005); Tahai and Meyer (1999); Walsh, Weber, and Margolis (2003)). We investigated a time frame for the period from 1960, when a significant expansion of the organization research domain started (Augier, March, and Sullivan (2005)), to 2008. We obtained access to these journals by using the Social Sciences Citation Index (SSCI) and EBSCO databases.

\subsection{CONCEPT IDENTIFICATION}

Suddaby $(2010,348)$ recently argued that "there is no clear agreement on the substantive definitional content of a construct". We therefore needed to find a pragmatic way to identify the concepts, and decided to refer to a term as a concept only when organization scholars explicitly label them as such. Furthermore, other field actors must approve this labelling. More than one author must label his or her work as a concept. Thus, a mutual agreement among field actors on what counts as a concept is a prerequisite for being included in our study.

To identify concepts of the organization studies field we started searching for the terms "concept" and "construct" in the titles, keywords, and abstracts in the following six scholarly journals: Administrative Science Quarterly, Academy of Management Review, Academy of Management Journal, Organization Science and Organization Studies. We choose these journals because they represent the main outlets for organizational research, and because within their respective prestige category, these journals are represented most frequently (Harzing (2003); Hennig-Thurau, Walsh, and Schrader (2006); Podsakoff et al. (2005); Tahai and Meyer (1999); Walsh, Weber, and Margolis (2003)). Within this first step of identification, we collected all words or combinations of words (excepting conjunctions, prepositions, articles, or numerals) that were connected with the signal-term "concept" and "construct", and which appeared both in the title and in the abstract, or alternatively twice in the abstract of an article, in a spreadsheet data file. 
Our next step in concept identification referred to the criterion for mutual agreement. The list of preliminary concepts had to be verified by organization scholars. Therefore, we analyzed whether the listed words and combination of words used to denominate one of our preliminary concepts were picked up at least twice in a top-tier management journal within the following ten years by another researcher, with reference to the originator of the concept ${ }^{1}$.

Our final step was to verify whether the identified concepts belong to the organization studies field. Here, we had to find a pragmatic way to handle the variety of theoretical approaches in the organization studies field. To be included in our study, a concept has to form part of a legitimated organization theory. To define the body of widely accepted organization theories, we referred to the categorizations applied within different handbooks of organization studies (Clegg et al. (2006); Hardy, Clegg, and Nord (1996); Hatch (1997); Kieser and Ebers (2006); Tsoukas and Knudsen (2003); Miner (2003)). This resulted in the following theories: Behavioral Theory of the Firm, Contingency Theory, Institutional Economics, Institutional Theory and Population Ecology. Our identification process resulted in a listing of 39 different organizational concepts (see Table I). For these 39 concepts we identified 2,033 articles in which these concepts are referred to.

\subsection{Diffusion of Concept Articles}

We conducted a bibliometric study to investigate the diffusion of the identified concepts (Giroux (2006); Heusinkveld and Benders (2001); Heusinkveld, Benders, and Koch (2000); Kieser (1997); Spell (1999)). We analyzed the diffusion throughout 39 management journals. To ensure that we included all concept-related articles, we also searched for synonyms, abbreviations, and slightly different word combinations for the concepts. For example, to analyze the diffusion of the concept "organizational slack", we also searched for "slack"; the concept "loose coupling" was also searched with "loosely coupled". We then studied the content of the articles by registering whether they refer to one of the identified concepts in title, abstract, and/or keywords. In total, the analysis resulted in a sample of 2,033 articles.

We are confident that this approach results in a body of concept-related articles. However, a researcher may refer to a concept in the abstract, yet the concept plays only a minor role in the article. The researcher's reference may be a rhetorical strategy to get the readers' attention rather than a real contribution to the research surrounding a particular concept. However, we assume that in most cases, the reference to a concept in title, keyword, and/ or abstract indicates that the concept retains importance throughout the article. We base our assumption on Mullins, Snizek, and Oehler $(1988,88)$ who argue that "keywords like title terms are content words [...] used to classify papers" and that "the abstract is a short, succinct summary of the scientific paper which is placed at the beginning of the work in order to allow the reader to determine if the paper is of interest".

1 A journal was considered a top-tier journal when appearing in the "A"-category of the Harzing listing (Harzing (2003)). 


\subsection{Analyses ANd MOdels}

We studied our assumptions on the basis of a frequency analysis and estimated the different effects on the diffusion of concept articles with an event history analysis. Central to event history analysis is the hazard model where the risk of experiencing an event at a certain point in time is predicted by using a set of covariates. The hazard rate $\lambda(t)$ to study the effects is defined as

$$
\lambda(t)=\lim [q(t, t+\Delta t) / \Delta t], \Delta t \rightarrow 0,
$$

where $q$ is the discrete probability of having an event between $t$ and $(t+\Delta t)$ conditional on the history of the process up to time $t$. This rate summarizes the information on the intervals of time between successive events, with higher values of the rate corresponding to shorter times between events and vice versa. In our study, an event occurs when a concept that has been previously introduced is referred to again in another article in one of the publications in our sample (rate of referring to concept articles). The hazard rate can have many forms, but an exponential model is not only the classical, but also the most robust, model (Blossfeld, Golsch, and Rohwer (2007)). Hence, this is the model we applied in this study. The exponential model, defined as $h_{0}(t)=\exp (\beta)$, assumes that the baseline hazard $h_{0}(t)$ is constant over time (Blossfeld, Golsch, and Rohwer (2007, 89)). We estimated all parameters by using the maximum likelihood approach with the STATA 11 program.

\subsection{VARIABLES}

Frequency: To measure the frequency we used the yearly counts of articles referring to an idea identified as a concept. We adjusted this number to the total number of published articles in the journals each year.

Diffusion of concept articles (rate of referring to concept articles): We measured this rate by using the number of months between a concept publication and the subsequent reference to this concept in another article. For example, if a concept article was published in February 2004 in one of the sample journals and the next article that referred to this concept occurred in a publication in September 2004, then the duration time was seven (months). If a concept was picked up twice within a month, then the number one was assigned to this observation.

Methodology: We gave each article a marker indicating the kind of methodology applied. We read titles, keywords, and abstracts of the articles to observe whether or not a concept is made the subject of an empirical study. We coded articles as (1), theoretical, if they contain no empirical data. Otherwise they were coded as empirical (0). We coded as (1), articles that apply quantitative methods (e.g., multiple regressions) in an additional category as empirical quantitative studies. We coded as (0), empirical qualitative, articles that apply qualitative research (e.g., case studies or qualitative interviews) (see for a similar approach Beyer, Chanove, and Fox (1995)). 
We used the following control variables in our model:

Age: We counted the age of a concept in months since its introduction. We do not expect a linear age effect. It is likely that newer concepts will be picked up more often. The introduction of a new concept can precipitate a controversial discussion, which is most likely for new concepts. Within this context, Cole and Cole (1967), for instance, study social stratification in science and observe that "[p]apers in physics now have a half-life of no more than five years; that is, at least half the citations in any year are to work published in the five preceding years" (Cole and Cole $(1967,380)$ ). Even if the Coles' sample of articles is drawn mostly from physics, we can assume that the same pattern also exists in other research fields, although probably with varying time spans.

Number of articles published per annum: To capture this variable we counted the number of published articles each year in the 39 journals. In many bibliometric studies that analyze the diffusion of concepts, the data is not adjusted to this variable (Giroux (2006)). However, this adjustment is important given that the number of articles per annum influences the diffusion of concepts. More publication outlets lead to an increase in publication possibilities.

Prestige of the journal: In general, articles in top-tier journals receive more attention than do articles in lower-ranking journals (Judge et al. (2007); Klamer and Van Dalen (2002); Starbuck (2005)). The impact factor is commonly used as an indicator of a journal's prestige. However, in the SSCI database, impact factors are only provided back to 1992 . Hence, to measure the journals' prestige for the years 1960 to 1991 we combined different journal rankings from different authors (Harzing (2003); Hennig-Thurau, Walsh, and Schrader (2006); Podsakoff et al. (2005); Starbuck (2005); Tahai and Meyer (1999); Walsh, Weber, and Margolis (2003)) ${ }^{2}$.

Time and number of previously published concept articles: We controlled for the time in months (period) and for the number of previously published concept articles of the same concept.

\section{Results}

\subsection{Descriptive Results}

On average, every concept is picked up about 52 times, with a minimum of one and a maximum of 172 articles. Figures $1 a$ and $1 b$ illustrate how frequently a particular concept is referred to in an article, i.e., the number of articles per concept. Concepts such as "principal and agent" (172 articles), "transaction cost" (168 articles), "institutional isomorphism" (161 articles), or "structural inertia" (151 articles) display the highest frequencies. Among the concepts with the lowest frequency are "liability of ageing" (one article), "location dependence" (two articles), "uncertainty absorption" (two articles), or "institutional work" (three articles).

2 We assume that a journal's prestige does not change much over time (Podsakoff et al. (2005); Starbuck (2005)). 
Figure 1a: Overview of frequency per concept

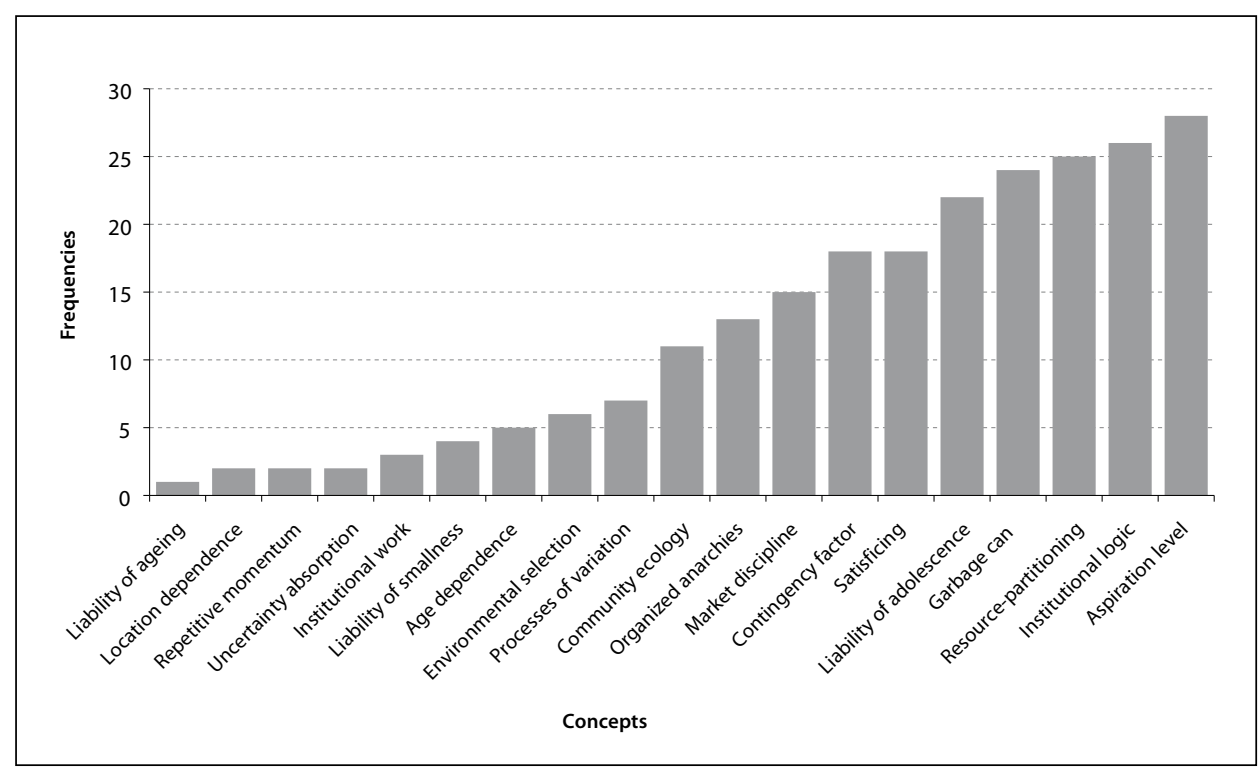

Figure 1b: Overview of frequency per concept (cont.)

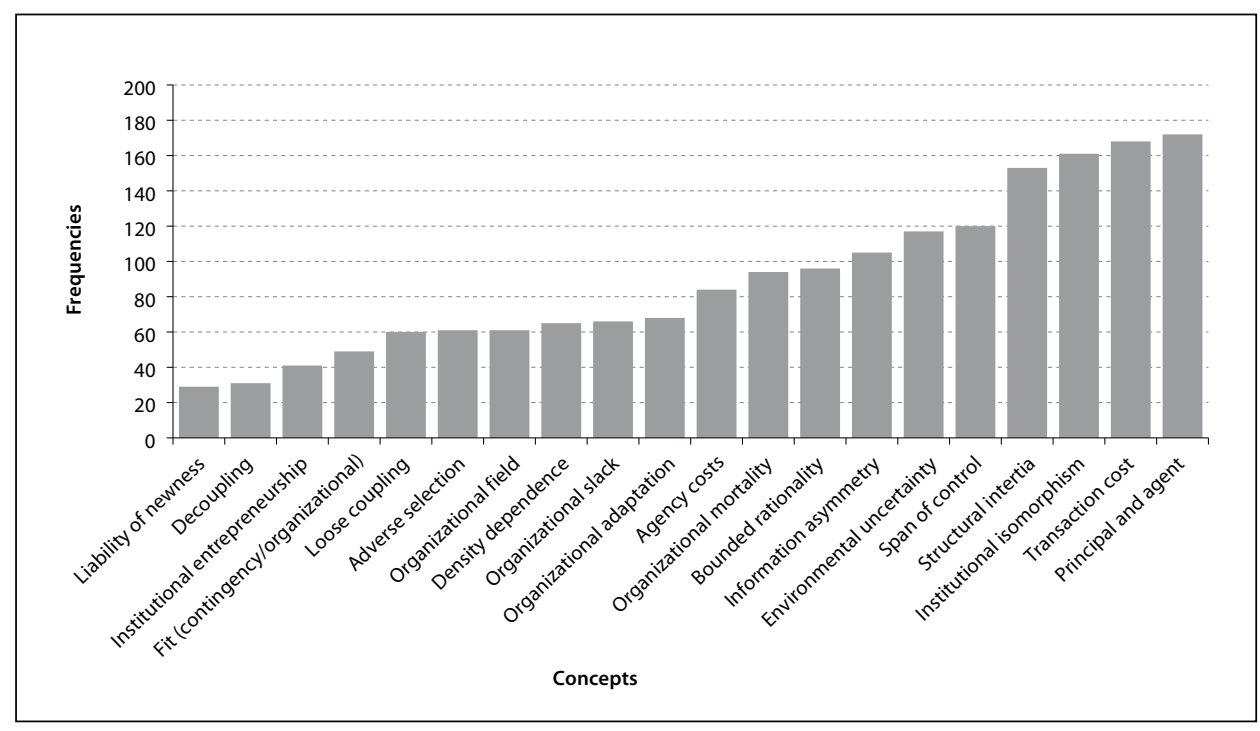


We suggested that the number of articles per year that are concerned with concepts increases over time. Figure 2 shows evidence for this assumption. The number of conceptrelated articles stays nearly constant until the years 1989/1990. From then on, the number of articles in which a concept is presented, empirically tested, or generally discussed shows a nearly continuous increase until the year 2008.

\section{Figure 2: Concept frequencies per annum}

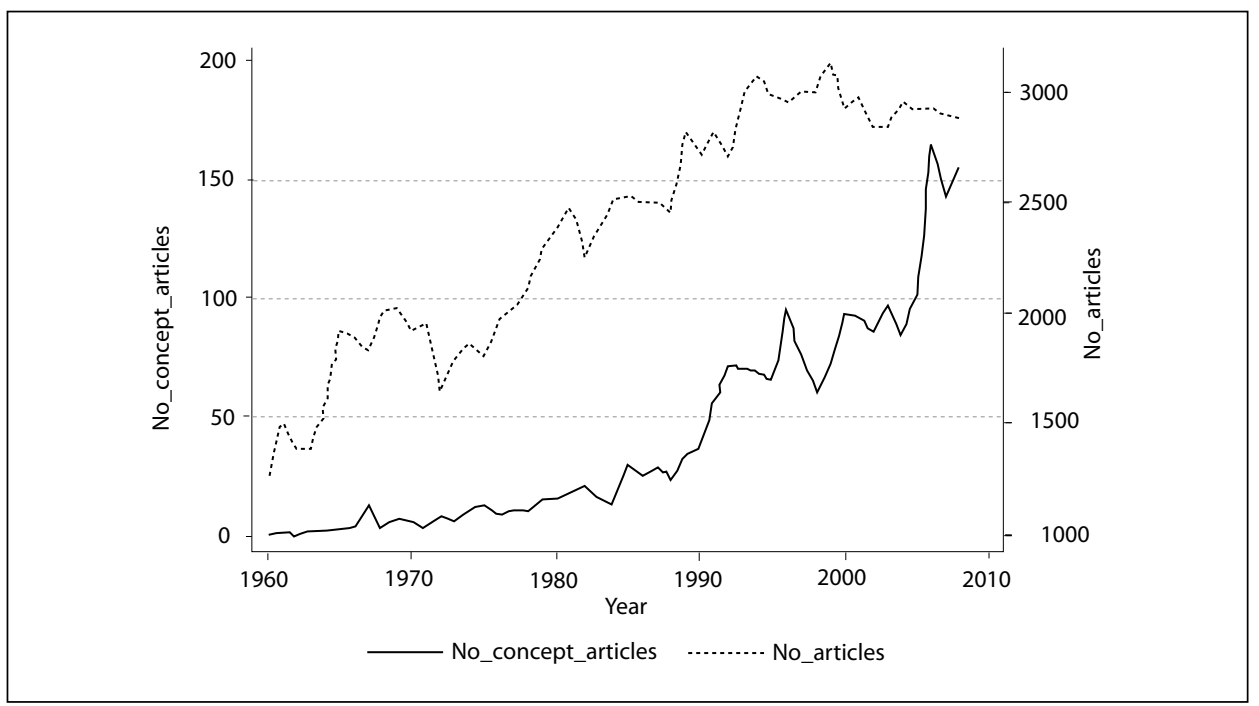

We see that in the year 1967 , the proportion of articles referring to concepts is $0.97 \%$ (13 articles) in relation to the total number of articles published. In 2006, the proportion is at its highest and has risen to $7.72 \%$ (165 articles). Recently, the number has declined to $7.33 \%$ in the year 2008 and $6.73 \%$ in the year 2007 (155 and 143 articles, respectively). Yet the overall trend indicates an increase of the number of articles that relate to concepts ${ }^{3}$.

We further assumed that the introduction of newly created concepts should decrease over time $^{4}$. Figure 3 indicates that in the period between 1960 and 1974, the number of newly introduced concepts continuously increases from only two new concepts between 1960

3 We believe that the low proportion of concept-related articles we find can be related to our method of identifying concepts: we require that the conceptual status be verified by at least two other researchers in top-tier journals. Thus, we do not include publications based on less-acknowledged concepts in our study.

4 It is important to note that our approach refers to the emergence of the identified concepts within the selected 39 journals. Hence, concepts that are introduced in monographs or editorial volumes are not considered as being "introduced" until they appear in one of the journals under study. 
and 1964 to 11 new concepts in the time frame from 1970 to $1974^{5}$. Since 1974 the number has decreased. In the period from the years 1980 to 1984 , the number is again very high in which six new concepts emerge within the publications under study. For the years 1985 to 2008, the number continuously decreases.

\section{Figure 3: Appearance of new concepts in articles}

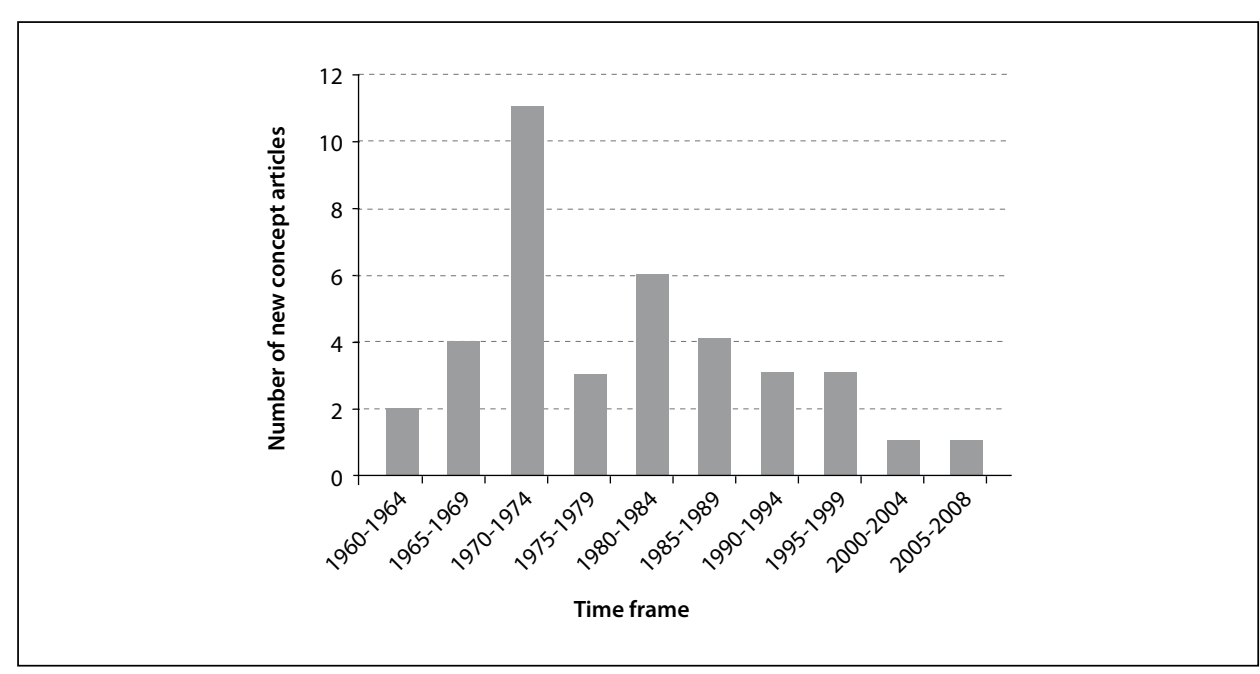

When we examine the question of whether reference to a concept occurs within an empirical study or in a theoretical piece of work, the data show that $64.44 \%$ of the 2,033 articles appear within an empirical research setting and $35.56 \%$ within theoretical articles. We assumed that the number of articles in which concepts are presented in an empirical, and especially a quantitative research setting, should increase over time. Figure 4 reflects this trend. Since the 1990s, the frequency of concept-related articles within an empirical research setting has shown a stronger increase than has the frequency of articles within a theoretical research setting. However, due to the small number of articles referring to concepts throughout the early years (e.g., 1960 to 1970), we must interpret the results with caution. Nevertheless, since the 1990s, the increase in concept-related empirical articles over concept-related theoretical articles is obvious. Furthermore, Figure 5 shows that since 1990, the number of concept-related empirical articles applying a quantitative method has increased on a greater scale than has the number of concept-related empirical articles in which qualitative research methods are applied. Quantitative methods clearly dominate here.

5 We aggregated the number of concept introductions over a time span of four years (respectively, three years from 2005 until 2008). 
Figure 4: Overview of concept frequencies (empirical and theoretical) per annum

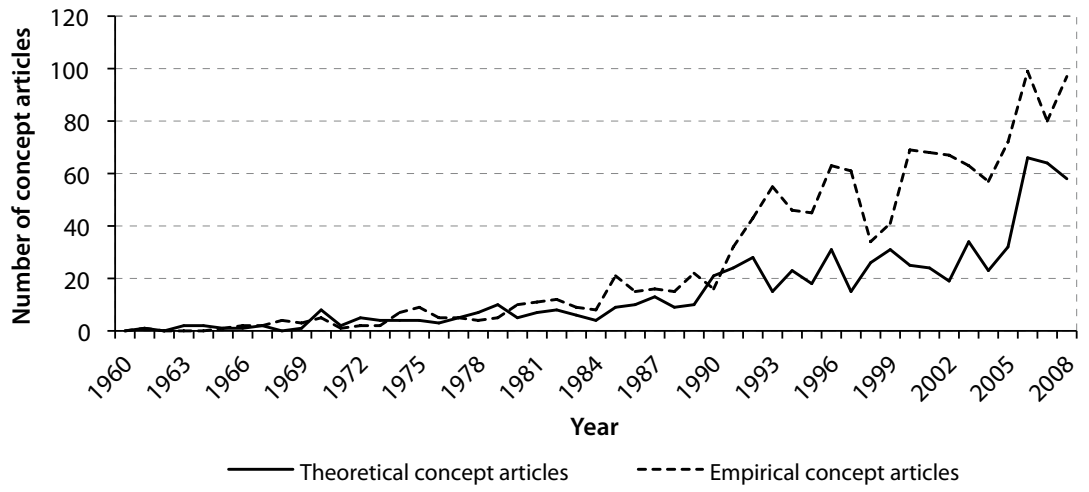

Figure 5: Overview of concept frequencies (quantitative and qualitative) per annum

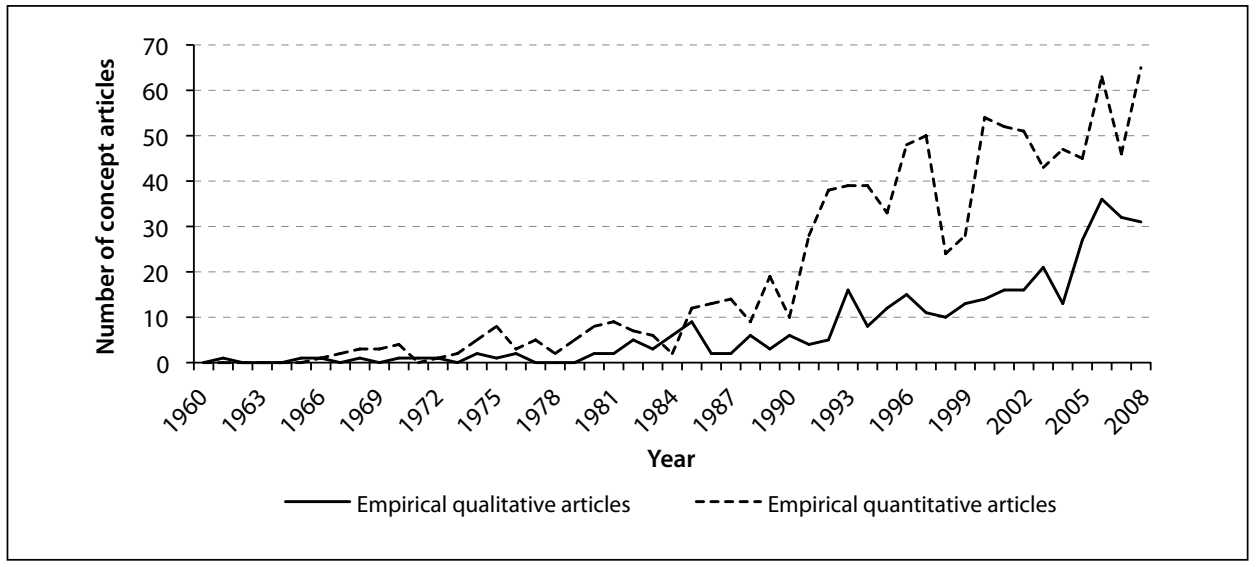

\subsection{Multivariate Results}

We examined Hypotheses 1, 2, and 3 by using an event history analysis. The first model in Table 1 presents our control variables. For the control variables we see that the variable "age" has a significant positive effect on the diffusion rate of concept articles, which implies that older concepts have a higher chance of being picked up again in another publication than do the newer ones. Furthermore, the total number of published articles in a year, the time period, and the number of previously published concept articles all have a significant positive effect on the diffusion rate of concept articles. The positive impact of the number of previously published concept articles on diffusion means that with 
every additional article published, the likelihood that a concept will get published again increases. Finally, the prestige of the journals in which the concept articles are published has a significant positive effect on the diffusion rate of concept articles.

In Hypothesis 1 we suggested that the diffusion of concept articles that present a methodology for quantitative research is higher than the diffusion of concept articles that do not offer such a methodology. Model 2 (Table 1) shows that the effect of a quantitative methodology on the diffusion rate of concept articles is positive and statistically significant. In Hypothesis 2 we assumed that the diffusion of articles in which concepts are empirically applied is higher than the diffusion of articles in which concepts are only theoretically discussed. Model 3 in Table 1 provides strong evidence for this assumption. The effect of a concept's empirical application on its diffusion rate is positive and statistically significant. Each additional empirical concept publication increases the rate of articles referring to this concept in another publication.

Table 1: Event history analysis models

\begin{tabular}{|c|c|c|c|c|}
\hline Variables & Model 1 & Model 2 & Model 3 & Model 4 \\
\hline Age of concept articles & $\begin{array}{l}0.01525^{* * *} \\
(0.0026)\end{array}$ & $\begin{array}{l}0.01487^{* * *} \\
(0.0027)\end{array}$ & $\begin{array}{l}0.01466^{* * *} \\
(0.00026)\end{array}$ & $\begin{array}{l}0.0118^{* * *} \\
(0.0027)\end{array}$ \\
\hline $\begin{array}{l}\text { Number of total articles } \\
\text { published p.a. }\end{array}$ & $\begin{array}{l}0.0004^{* *} \\
(0.0001)\end{array}$ & $\begin{array}{l}0.0003^{* *} \\
(0.0001)\end{array}$ & $\begin{array}{l}0.0004^{* *} \\
(0.0001)\end{array}$ & $\begin{array}{l}0.0004^{* * *} \\
(0.0001)\end{array}$ \\
\hline Prestige journal & $\begin{array}{l}0.0775^{* *} \\
(0.0255)\end{array}$ & $\begin{array}{l}0.0662^{*} \\
(0.0263)\end{array}$ & $\begin{array}{l}0.0815^{* *} \\
(0.0258)\end{array}$ & $\begin{array}{l}0.0776^{* *} \\
(0.0259)\end{array}$ \\
\hline Period & $\begin{array}{l}0.10463^{* * *} \\
(0.005)\end{array}$ & $\begin{array}{l}0.1012^{* * *} \\
(0.0051)\end{array}$ & $\begin{array}{l}0.09961^{* * * *} \\
(0.0051)\end{array}$ & $\begin{array}{l}0.0977^{* * *} \\
(0.0051)\end{array}$ \\
\hline $\begin{array}{l}\text { Number of previously } \\
\text { published concept articles }\end{array}$ & $\begin{array}{c}0.0003^{*} \\
(0.0002)\end{array}$ & $\begin{array}{c}0.0003^{*} \\
(0.0002)\end{array}$ & $\begin{array}{c}0.0003^{*} \\
(0.0002)\end{array}$ & $\begin{array}{c}0.0003 \\
(0.0002)\end{array}$ \\
\hline Empirical & & & $\begin{array}{l}0.1969^{* * *} \\
(0.0555)\end{array}$ & $\begin{array}{l}0.1714^{* *} \\
(0.0557)\end{array}$ \\
\hline Empirical - qualitative & & $\begin{array}{c}0.0321 \\
(0.0758)\end{array}$ & & \\
\hline Empirical - quantitative & & $\begin{array}{l}0.2468^{* * *} \\
(0.0573)\end{array}$ & & \\
\hline $\begin{array}{l}\text { Introduction concept } \\
\text { theoretically }\end{array}$ & & & & $\begin{array}{l}-0.2453^{* * *} \\
(0.0493)\end{array}$ \\
\hline _cons & $-212.27^{* * *}$ & $-205.28^{* * *}$ & $-202.34^{* * *}$ & $-198.34^{* * *}$ \\
\hline \multicolumn{5}{|l|}{ Statistics } \\
\hline Chi-square & 1066.74 & 1043.21 & 1028.35 & 1054.30 \\
\hline df & 5 & 7 & 6 & 7 \\
\hline Observation Spells & 11,642 & 11,267 & 11,267 & 11,267 \\
\hline
\end{tabular}


Hypothesis 3 related to the question of whether the empirical application of a concept has any effect on its diffusion right from its first introduction to the scientific community. Several authors doubt that this favors a concept's diffusion. Instead, they argue that theoretically introduced concepts provide more "food for thought" and are thus more intriguing. Therefore, we assumed that a concept introduced in a theoretical article is more likely to diffuse. However, the model 4 presented in Table 1 indicates that this assumption cannot be supported. In contrast to our hypothesis, the introduction of a concept theoretically has a significant negative effect on its diffusion.

\section{Discussion and Conclusion}

Our paper generally adds to understanding the dynamics in the organization studies field. We extend earlier research on concepts by focusing not on selected concepts, but by considering the historical development of the field as a whole through the lens of concepts. In doing so, we provide empirical evidence for the increasing importance of concepts in our field and reasoning for the question of why certain kinds of concept take hold while others do not. Thus, our study not only follows organization scholars' recent plea for investigating the role of concepts in our field (Suddaby (2010); Colquitt and Zapata-Phelan (2007)). It also contributes to our knowledge on how the organization studies field evolved, and which logics were prominent in which periods of time, aspects that are reflected in the kinds of concepts applied.

The discourse in organization studies suggests that novelty and originality are positively rated by reviewers, and thus increase the likelihood of an article being published (Staw (1995)). For instance, McKinley (2010) argues that the primary goal of in the discipline in the 1960s and 1970s was to achieve consensus on the validity status of theories, but today, the main aim appears to be the development of new theory. Comparably, Colquitt and Zapata-Phelan $(2007,1295)$, in an analysis of theory building and theory testing in the Academy of Management Journal, find a recent trend towards theory development. However, the results of our study suggest otherwise. While organization scholars indeed refer to concepts more often in their articles - and, as we argued, the increasing reference to concepts can be due to their role of balancing the demand for novelty and continuity -, there is a tendency to reuse existing concepts at the expense of developing new concepts. Our results thus provide empirical evidence on the existence of a confirmation bias in the application of concepts that has been noted critically but, so far, mainly conceptually by other scholars in the field (Barley (2006); De Rond and Miller (2006)).

The existence of a confirmation bias becomes comprehensible in the light of the increasing uncertainty in the field of organization studies. Both young and experienced scholars are expected to publish in prestigious scholarly journals to legitimate their membership in the field and to build or to defend their position. With only a few prestigious journals and high rejection rates (the Academy of Management Journal, for instance, has an acceptance rate of approximately 8\% (Rynes (2005)), competition in the publishing market is high. 
Furthermore, scholars face what Whitley (2000) refers to as strategic task uncertainty: the lack of standardized and commonly accepted criteria to evaluate the value of new knowledge. The existing paradigms in organization studies do not serve as an indisputable guideline to derive appropriate research practices. They represent competing logics, and even within each paradigm there are struggles about what should count as theoretical development and how it should be evaluated. The results of our study support the assumption that in such an uncertain situation, the individual scholar tends to act according to the institutional logic that dominates the field. This result extends earlier research in institutional theory on the influence of institutional logics on field activities (e.g., Lounsbury (2002); Thornton and Ocasio (1999)) by pointing to the role of uncertainty in explaining field-level outcomes such as, in the given case, the continued dominance of a particular logic. It thereby contributes to the recent interest in the co-existence of logics (e.g., Lounsbury (2007); Marquis and Lounsbury (2007); Reay and Hinings (2005); Reay and Hinings (2009)). Our study suggests that when competing logics co-exist in a field among which a particular logic prevails, its dominance will be reproduced in situations of uncertainty in which actors seek to find guidance by referring to the most institutionalized practices.

The results of our study show that concepts in organization studies are mainly applied in research according to the logic of positivism, and this predominance is reproduced over several decades. It is only speculative to debate what can explain positivism's hegemony and whether it can defend its position as the dominant logic in the field of organization studies. The positivist paradigm may benefit from the more general "trust in numbers" or "mystique of quantity" (Kaplan $(1964,172)$ ) remarkable in other societal spheres as well (Best (2001); Porter (1995); Porter (1996)). "The evolution of any particular field is embedded in the evolutionary ecology of many fields" (Augier, March, and Sullivan $(2005,93))$. Thus, acting also in other fields of society in which quantification is a takenfor-granted characteristic of many day-to-day practices, organization scholars may tend towards a logic that is in line with these deeply held assumptions and beliefs. Furthermore, compared to other research paradigms, positivism provides at least a more standardized list of criteria to evaluate the rigor of a paper (Kieser (2007)). From the positivist perspective, rigor stems in part from the application of sophisticated statistical tests, and reviewers tend to regard high-level statistics as an indicator of rigor (Beyer, Chanove, and Fox (1995); Staw (1995)). Committed to norms of fairness in the process of evaluating manuscripts, reviewers may rely on a "faith in objectivity" (Porter $(1995,8)$ ), the deep-seated belief in the fairness of supposedly "objective" quantitative methods. Thus, positivism may benefit from a generalized belief in its objectivity that is widespread in our society.

However, the existence of other paradigms leaves at least a little room for ongoing struggles and for change, given that heterogeneity and competition are an important source for institutional change (Clemens and Cook (1999)). Although a particular logic may dominate in a particular period of time, this dominance can change throughout the next period. Institutional logics are always the result of social processes in a field (Friedland and Alford (1991)). If actors, and especially the powerful ones, continuously act according to 
another logic, the formerly dominant logic may lose its appeal and other actors in the field are likely to follow (Lawrence and Suddaby (2006); Suddaby and Greenwood (2005)). Furthermore, logic blending, or the convergence of an alternative logic that combines traces of different logics (Glynn and Lounsbury (2005); Mars and Lounsbury (2009)) can also be likely. There are tendencies in the field to combine the advantages of positivism and constructivism by introducing a third, alternative logic based on critical realism (e.g., Leca and Naccache (2006)), or on practice theories (e.g., Schatzki (2005)). Hence, in the field of organization studies, if editors of top-tier journals publish articles that align with alternative logics such as constructivism or realism; if researchers with a high reputation and central positions in organization studies and most of its subfields pursue their work in the tradition of non-positivist logics; and if the programs of leading scholarly conferences continue to represent the diversity of organization studies, then there is always the potential for an institutional change that will end the hegemony of positivism as the dominant logic in the field of organization studies.

\section{APPENDIX}

\section{Table I: Concepts and related organization theory}

\begin{tabular}{|c|c|}
\hline Concept & Theoretical framework \\
\hline $\begin{array}{l}\text { Aspiration level, bounded rationality, garbage } \\
\text { can, loose coupling, organizational slack, organ- } \\
\text { ized anarchies, satisficing, uncertainty absorption }\end{array}$ & Behavioral Theory of the Firm \\
\hline $\begin{array}{l}\text { Market discipline, adverse selection (hidden in- } \\
\text { formation), agency cost, information asymmetry, } \\
\text { principal and agent, transaction cost }\end{array}$ & Institutional Economics \\
\hline $\begin{array}{l}\text { Decoupling, institutional entrepreneur, institutio- } \\
\text { nal logic, institutional work, isomorphism, organi- } \\
\text { zational field }\end{array}$ & Institutional Theory \\
\hline $\begin{array}{l}\text { Fit (structural/organizational) or congruence, } \\
\text { span of control, contingency factor, environmen- } \\
\text { tal uncertainty }\end{array}$ & Contingency Theory \\
\hline $\begin{array}{l}\text { Organizational/structural adaptation, age de- } \\
\text { pendence, community ecology, location depend- } \\
\text { ence, repetitive momentum, resource-partition- } \\
\text { ing, processes of variation/selection/retention, } \\
\text { density dependence, environmental selection, } \\
\text { liability of adolescence, liability of ageing, liability } \\
\text { of newness, liability of smallness, organizational } \\
\text { mortality, structural inertia }\end{array}$ & Population Ecology \\
\hline
\end{tabular}




\section{S. BORT/S. SCHILLER-MERKENS}

\section{References}

Augier, Mie, James March, and Bilian Sullivan (2005), Notes on the evolution of a research community: Organization studies in anglophone North America, 1945-2000, Organization Science 16, 85-95.

Bacharach, Samuel (1989), Organizational theories: Some criteria for evaluation, Academy of Management Review 14, 496-515.

Bagozzi, Richard and Lynn Phillips (1982), Representing and testing organizational theories: A holistic construal, Administrative Science Quarterly 27, 459-489.

Barley, Stephen (2006), When I write my masterpiece: Thoughts on what makes a paper interesting, Academy of Management Journal 49, 16-20.

Bartunek, Jean, Sara Rynes, and Duane Ireland (2006), Academy of Management Journal editors' forum: What makes management research interesting, and why does it matter?, Academy of Management Journal 49, 9-15.

Beckert, Jens (1999), Agency, entrepreneurs, and institutional change. The role of strategic choice and institutionalized practices in organizations, Organization Studies 20, 777-799.

Best, Joel (2001), Damned Lies and Statistics: Untangling the Numbers from the Media, Politicians, and Activists, Berkeley: University of California Press.

Beyer, Janice, Roland Chanove, and William Fox (1995), The review process and the fates of manuscripts submitted to AMJ, Academy of Management Journal 38, 1219-1260.

Blossfeld, Hans-Peter, Katrin Golsch, and Götz Rohwer (2007), Event History Analysis with Stata, New York: Lawrence Erlbaum Associates.

Burrell, Gibson and Gareth Morgan (1979), Sociological Paradigms and Organisational Analysis: Elements of the Sociology of Corporate Life, London: Heinemann Educational Books.

Camic, Charles and Yu Xie (1994), The statistical turn in American social science: Columbia University, 1890 to 1915, American Sociological Review 59, 773-805.

Carnap, Rudolph (1995), An Introduction to the Philosophy of Science, New York: Dover Publications.

Clegg, Stewart R., Cynthia Hardy, Thomas B. Lawrence, and Walter R. Nord (2006), The Sage Handbook of Organization Studies, $2^{\text {nd }}$ ed., London: Sage.

Clemens, Elisabeth S. and James M. Cook (1999), Politics and institutionalism: Explaining durability and change, Annual Review of Sociology 25, 441-466.

Cole, Stephen and Jonathan Cole (1967), Scientific output and recognition: A study in the operation of the reward system in science, American Sociological Review 32, 377-390.

Colquitt, Jason and Cindy Zapata-Phelan (2007), Trends in theory building and theory testing: A five-decade study of the Academy of Management Journal, Academy of Management Journal 50, 1281-1303.

Daft, Richard (1980), The evolution of organization analysis in ASQ, 1959-1979, Administrative Science Quarterly 25, 623-636.

Daft, Richard, Ricky Griffin, and Valerie Yates (1987), Retrospective accounts of research factors associated with significant and not-so-significant research outcomes, Academy of Management Journal 30, 763-785.

De Rond, Mark and Alan Miller (2006), Publish or perish: Bane or boon of academic life?, Journal of Management Inquiry 14, 321-329.

Denison, Daniel (1996), What is the difference between organizational culture and organizational climate? A native's point of view on a decade of paradigm wars, Academy of Management Review 21, 619-654.

Dubin, Robert (1969), Theory Building, New York: The Free Press.

Engwall, Lars (1998), Mercury and minerva: A modern multinational academic business studies on a global scale, in José L. Alvarez (ed.), The Diffusion and Consumption of Business Knowledge, London: Macmillan Press, 81-109.

Field, Richard H. G. (1993), The case of the purloined journal article, or on being at the receiving end of academic dishonesty, Journal of Management Inquiry 2, 317-324. 
Frey, Bruno (2003), Publishing as prostitution? Choosing between one's own ideas and academic success, Public Choice 116, 205-223.

Frey, Bruno and Margit Osterloh (2006), Evaluations: Hidden costs, questionable benefits, and superior alternatives, Working Paper, Center for Research in Economics, Management and the Arts, Zurich.

Friedland, Roger and Robert Alford (1991), Bringing society back in: Symbols, practices, and institutional contradictions, in Walter W. Powell, and Paul J. DiMaggio (eds.), The New Institutionalism in Organizational Analysis, Chicago: University of Chicago Press, 232-263.

Frost, Peter and Ronald Taylor (1995), Partisan perspective. A multiple-level interpretation of the manuscript review process in social science journals, in Peter Frost, Anne Huff, Benjamin Schneider, Susan Taylor, and Andrew Van de Ven (eds.), Rhythms of Academic Life. Personal Accounts of Careers in Academia, Thousand Oaks, California: Sage, 13-84.

Giroux, Hélène (2006), 'It was such a handy term': Management fashions and pragmatic ambiguity, Journal of Management Studies 43, 1227-1260.

Glynn, Mary Ann and Michael Lounsbury (2005), From the critics' corner: Logic blending, discursive change and authenticity in a cultural production system, Journal of Management Studies 42, 1031-1055.

Hannan, Michael and John Freeman (1977), The population ecology of organizations, American Journal of Sociology 82, 929-964.

Hardy, Cynthia, Stewart R. Clegg, and Walter R. Nord (1996), Handbook of Organization Studies, London: Sage.

Hardy, Cynthia and Steve Maguire (2008), Institutional entrepreneurship, in Royston Greenwood et al. (eds.), The Sage Handbook of Organizational Institutionalism, London: Sage, 198-217.

Harzing, Anne-Wil (2003), Journal Quality List, www.harzing.com, University of Melbourne, Australia.

Hatch, Mary Jo (1997), Organization Theory, New York: Oxford University Press.

Hempel, Carl (1974), Grundzüge der Begriffsbildung in der empirischen Wissenschaft, Düsseldorf: Bertelsmann Universitätsverlag.

Hennig-Thurau, Thorsten, Gianfranco Walsh, and Ulf Schrader (2006), VHB-Jourqual - Ein Ranking von betriebswirtschaftlich relevanten Zeitschriften auf der Grundlage von Urteilen der VHB-Mitglieder, VHB http://www.v-h-b.de.

Heusinkveld, Stefan and Jos Benders (2001), Surges and sediments: Shaping the reception of reengineering, Information \& Management 38, 239-251.

Heusinkveld, Stefan, Jos Benders, and Christian Koch (2000), Dispersed discourse: Defining the shape of BPR in Denmark and the Netherlands, Working Paper, $16^{\text {th }}$ EGOS Colloquium, Helsinki.

Hirsch, Paul and Daniel Levin (1999), Umbrella advocates versus validity police: A life-cycle model, Organization Science 10, 199-213.

Jermier, John M. (1992), Literary methods and organization science: Reflections on "when in sleeper wakes", in Peter J. Frost and Ralph E. Stablein (eds.), Doing Exemplary Research, Newbury Park, California: Sage, 210-226.

Judge, Timothy, Daniel Cable, Amy Colbert, and Sara Rynes (2007), What causes a management article to be cited: Article, author, or journal? Academy of Management Journal 50, 491-506.

Kaplan, Abraham (1964), The Conduct of Inquiry: Methodology for Behavioral Science, San Francisco: Chandler Publishing Company.

Khurana, Rakesh (2007), From Higher Aims to Hired Hands: The Social Transformation of American Business Schools and the Unfulfilled Promise of Management as a Profession, Princeton: Princeton University Press.

Kieser, Alfred (1997), Moden \& Mythen des Theoretisierens über die Organisation, in Hans Jürgen Drumm and Christian Scholz (eds.), Individualisierung als Paradigma, Stuttgart: Kohlhammer, 235-259.

Kieser, Alfred (2007), Entwicklung von Organisationstheorien als Zeitgeistphänomen, zfbf59, 674-701.

Kieser, Alfred and Mark Ebers (2006), Organisationstheorien, Stuttgart: Kohlhammer.

Klamer, Arjo and Hendrik Van Dalen (2002), Attention and the art of scientific publishing, Journal of Economic Methodology 9, 289-315. 


\section{S. BORT/S. SCHILLER-MERKENS}

Knudsen, Christian (2003), Pluralism, scientific progress, and the structure of organization theory, in Haridimos Tsoukas and Christian Knudsen (eds.), The Oxford Handbook of Organization Theory, Oxford: Oxford University Press, 262-286.

Kuhn, Thomas (1962), The Structure of Scientific Revolutions, Chicago: University of Chicago Press.

Landry, Maurice (1995), A note on the concept of 'problem', Organization Studies 16, 315-343.

Lane, Peter, Balaji Koka, and Seemantini Pathak (2006), The reification of absorptive capacity: A critical review and rejuvenation of the construct, Academy of Management Review 31, 833-863.

Lawrence, Thomas B. and Roy Suddaby (2006), Institutions and institutional work, in Stewart R. Clegg, Cynthia Hardy, Thomas B. Lawrence, and Walter Nord (eds.), The Sage Handbook of Organization Studies, $2^{\text {nd }}$ ed., London: Sage, 215-254.

Leca, Bernard and Philippe Naccache (2006), A critical realist approach to institutional entrepreneurship, Organization 13, 627-651.

Lounsbury, Michael (2002), Institutional transformation and status mobility: The professionalization of the field of finance, Academy of Management Journal 45, 255-266.

Lounsbury, Michael (2007), A tale of two cities: Competing logics and practice variation in the professionalization of mutual funds, Academy of Management Journal 50, 289-307.

Marquis, Christopher and Michael Lounsbury (2007), Vive la résistance: Competing logics and the consolidation of U.S. community banking, Academy of Management Journal 50, 799-820.

Mars, Matthew M. and Michael Lounsbury (2009), Raging against or with the private marketplace: Logic hybridity and eco-entrepreneurship, Journal of Management Inquiry 18, 4-13.

McKinley, William (2010), Organizational theory development: Displacement of ends?, Organization Studies 31, 47-68.

McKinley, William, Mark Mone, and Gyewan Moon (1999), Determinants and development of schools in organization theory, Academy of Management Review 24, 634-648.

Miller, Chet (2006), Peer review in the organizational and management sciences: Prevalence and effects of reviewer hostility, bias, and dissensus, Academy of Management Journal 49, 425-431.

Miner, John B. (2003), The rated importance, scientific validity, and practical usefulness of organizational behavior theories: A quantitative review, Academy of Management Learning and Education 2, 250-268.

Mizruchi, Mark S. and Lisa C. Fein (1999), The social construction of organizational knowledge: A study of the uses of coercive, mimetic, and normative isomorphism, Administrative Science Quarterly 44, 653-683.

Morgan, Gareth (1979), Response to Mintzberg, Administrative Science Quarterly 24, 137-139.

Mowday, Richard (1997), Celebrating 40 years of the Academy of Management Journal, Academy of Management Journal 40, 1400-1413.

Mullins, Nicolas C., William Snizek, and Kay Oehler (1988), The structural analysis of a scientific paper, in A. F. J. Van Raan (ed.), Handbook of Quantitative Studies of Science and Technology, Amsterdam: Elsevier Science Publishers, 81-105.

Nodoushani, Omid (2000), Epistemological foundations of management theory and research methodology, Human Systems Management 19, 71-81.

Osigweh, Chimezie (1989), Concept fallibility in organizational science, Academy of Management Review 14, 579-594.

Pfeffer, Jeffrey (1993), Barriers to the advance of organizational science: Paradigm development as a dependent variable, Academy of Management Review 18, 599-620.

Pfeffer, Jeffrey (2005), Why do bad management theories persist? A comment on Ghoshal, Academy of Management Learning and Education 4, 96-100.

Podsakoff, Philip M., Scott B. MacKenzie, Daniel G. Bachrach, and Nathan P. Podsakoff (2005), The influence of management journals in the 1980s and 1990s, Strategic Management Journal 26, 473-488. 
Picot, Arnold, Ralf Reichwald, and Rolf Wigand (2008), Information, Organization and Management, Berlin/Heidelberg: Springer-Verlag.

Porter, Theodore M. (1995), Trust in Numbers: The Pursuit of Objectivity in Science and Public Life, Princeton: Princeton University Press.

Porter, Theodore M. (1996), Making things quantitative, in Michael Power (ed.), Accounting and Science: Natural Inquiry and Commercial Reason, Cambridge: Cambridge University Press, 36-56.

Pratt, Michael G. (2009), For the lack of a boilerplate: Tips on writing up (and reviewing) qualitative research, Academy of Management Journal 52, 856-862.

Reay, Trish and C. R. Hinings (2005), The recomposition of an organizational field: Health care in Alberta, Organization Studies 26, 351-384.

Reay, Trish and C. R. Hinings (2009), Managing the rivalry of competing institutional logics, Organization Studies 30, 629-652.

Reed, Michael (2006), Organizational theorizing: A historically contested terrain, in Stewart R. Clegg, Cynthia Hardy, Thomas B. Lawrence, and Walter R. Nord (eds.), The Sage Handbook of Organization Studies, $2^{\text {nd }}$ ed., London: Sage, 19-54.

Rynes, Sara (2005), From the editors. Taking stock and looking ahead, Academy of Management Journal 48, 9-15.

Schatzki, Theodore (2005), The sites of organizations, Organization Studies 26, 465-484.

Scherer, Andreas G. (2003), Modes of explanation in organization theory, in Haridimos Tsoukas and Christian Knudsen (ed.), The Oxford Handbook of Organization Theory, Oxford: Oxford University Press, 310-344.

Schminke, Marshall and Marie Mitchell (2003), From the editors. In the beginning ..., Academy of Management Journal 46, 279-282.

Shenhav, Yehouda, Wesley Shrum, and Sigal Alon (1994), 'Goodness' concepts in the study of organizations: A longitudinal survey of four leading journals, Organization Studies 15, 753-776.

Spell, Chester S. (1999), Where do management fashions come from, and how long do they stay? Journal of Management History 5, 334-348.

Starbuck, William (2005), How much better are the most-prestigious journals? The statistics of academic publication, Organization Science 16, 180-200.

Staw, Barry (1995), Repairs on the road to relevance and rigor. Some unexplored issues in publishing organizational research, in L. L. Cummings and Peter Frost (eds.), Publishing in the Organizational Sciences, Thousand Oaks, California: Sage, 85-97.

Stevenson, William, Jone Pearce, and Lyman Porter (1985), The concept of "coalition" in organization theory and research, Academy of Management Review 10, 256-268.

Suddaby, Roy (2010), Construct clarity in theories of management and organization, Academy of Management Review 35, 346-357.

Suddaby, Roy and Royston Greenwood (2005), Rhetorical strategies of legitimacy, Administrative Science Quarterly 50, 35-67.

Sutton, Robert and Barry Staw (1995), What theory is not, Administrative Science Quarterly 40, 371-384.

Tahai, Alireza and Michael Meyer (1999), A revealed preference study of management journals' direct influences, Strategic Management Journal 20, 279-296.

Thornton, Patricia H. and William Ocasio (1999), Institutional logics and the historical contingency of power in organizations: Executive succession in the higher education publishing industry, 1958-1990, American Journal of Sociology 105, 801-843.

Tsoukas, Haridimos and Christian Knudsen (2003), The Oxford Handbook of Organization Theory, Oxford: Oxford University Press. 


\section{S. BORT/S. SCHILLER-MERKENS}

Verbeke, Willem, Marco Volgering, and Marco Hessels (1998), Exploring the conceptual expansion within the field of organizational behaviour: Organizational climate and organizational culture, Journal of Management Studies 35, 303-329.

Von Weizsäcker, Ernst (1974), Erstmaligkeit und Bestätigung als Komponenten der pragmatischen Information, in Ernst von Weizsäcker (ed.), Offene Systeme I. Beiträge zur Zeitstruktur von Information, Entropie und Evolution, Stuttgart: Ernst Klett Verlag, 82-113.

Walsh, James, Klaus Weber, and Joshua Margolis (2003), Social issues and management: Our lost cause found, Journal of Management 29, 859-881.

Weingart, Peter and Sabine Maasen (1997), The order of meaning: The career of chaos as a metaphor, Configurations $463-520$

Whitley, Richard (2000), The Intellectual and Social Organization of the Sciences, Oxford: Oxford University Press. 